\title{
Features of calculation and design of complex concrete monolithic slabs
}

\author{
Vitaly Kuznetsov and Yulia Shaposhnikova* \\ Moscow State University of Civil Engineering, Yaroslavskoe shosse, 26, Moscow, 129337, Russia
}

\begin{abstract}
In the article features of designing of reinforced concrete floors on the profiled flooring, leaning against steel I-beams are considered. Specific features of calculating the strength of composite slabs in accordance with JV 35.13330.2011 "Bridges and pipes" and SP 266.1325800.2016 "Structural concrete structures. Design rules". A method for determining the forces based on the real ratio of the rigidity of the overlap elements is also considered. The analysis of the results of the numerical experiment made it possible to establish the optimum coefficients of the use of materials that can be used in the design of combined overlaps.
\end{abstract}

\section{Introduction}

In the article features of calculation of durability of the combined beams of overlap executed in accordance with SP 35.13330.2011 «Bridges and pipes» and SP 266.1325800.2016 «Steel reinforced concrete structures. Design rules ", and also by means of a calculation based on the distribution of forces in accordance with the rigidity of the overlap elements. In order to obtain efficient and least material-intensive structures, overlaps were investigated in the range of design loads from 15 to $60 \mathrm{~kg} / \mathrm{m}$ for I-beam type $35 \mathrm{~B} 1$. The analysis and comparison of the results are performed, recommendations on the design of such structures are formulated.

Many Russian and foreign scientists were studying the work of complex monolithic ceilings, supported on metal beams. For example, in [1-3] the questions of the relevance of the use of such structures in buildings of various purposes have been studied. Features of calculations of such overlaps are presented in the studies [4-14].

Traditionally, the calculation of strength was carried out in accordance with the distribution of forces, in proportion to the rigidity of the components of the overlap [15]. Since 1984, the calculation of composite structures has been carried out in accordance with [16] and its subsequent versions [17], and in 2017 a normative document [18] has been introduced, which to some extent duplicates the provisions of previous standards. At present, in Russia it is recommended to calculate the steel-reinforced concrete structures in accordance with [18].

\footnotetext{
* Corresponding author : yuliatalyzova@yandex.ru
} 


\section{Methods}

The object of the study is a monolithic complex overlap, hinged on the rolling beams $35 \mathrm{~B} 1$, steel grade C345. Estimated span of beams 6m, step 3m. Concrete - heavy, class B15, profiled flooring - brand H75-700 with a thickness of $0.7 \mathrm{~mm}$, the maximum thickness of reinforced concrete slab is $125 \mathrm{~mm}$. The total design load $q$ on the overlap varied from 5.0 to $20.0 \mathrm{kN} / \mathrm{m}^{2}$. The calculated load on the beam $q_{b}$ from 15 to $60 \mathrm{kN} / \mathrm{m}^{2}$ (Figure1).

a)

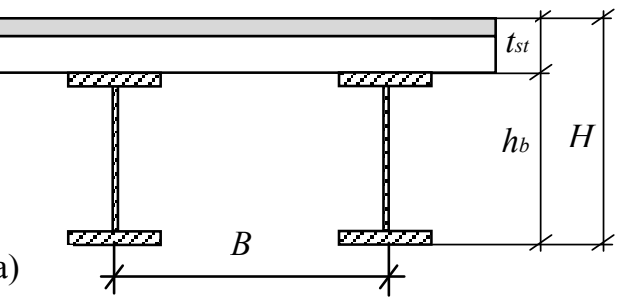

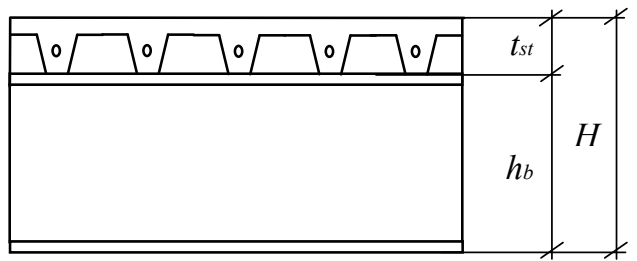

b)

Fig. 1. The overlapping scheme. a) - the cross section of the overlap, b) - the longitudinal section of the overlap. $t_{s t}$ - the height of the overlap taking into account the profiled flooring, $h_{b}$ - the height of the steel beam, $H$ - the total height of the floor, $B$ - the distance between the axes of the steel beams

According to [15], in such a construction, the total bending moment Mex is perceived by a reinforced concrete slab over the profiled floor $\left(M_{1 e x}\right)$ and metal beams $\left(M_{2 e x}\right)$

$$
M_{e x}=M_{1 e x}+M_{2 e x} \text {. }
$$

The distribution of the moments is directly proportional to the ratio of the rigidity $B$ of these components

$$
M_{1 e x} / M_{2 e x}=\mathrm{B}_{1} / \mathrm{B}_{2} \text {. }
$$

Rigidity of a monolithic reinforced concrete floor over profiled flooring $B_{g b}$

$$
B_{1}=B_{g b}=0,85 \cdot E_{b} \cdot I_{n},
$$

$E_{b}$ - modulus of elasticity of concrete; $I_{n}=\left(b_{f}{ }^{\prime} \cdot h_{f}{ }^{\prime}\right) / 12$ - moment of inertia of reinforced concrete section; $b_{f}^{\prime}$ и $h_{f}^{\prime}$ - width and height of the flange of the T-section.

The stiffness of an I-beam

$$
B_{2}=B_{I}=0,85 \cdot E_{s} \cdot I_{I},
$$

$E_{s}$ - modulus of elasticity of steel; $I_{I}$ - moment of inertia of the beam.

The maximum bending moment of a metal beam

$$
M=R_{y} \cdot W_{n, \min } \cdot \gamma_{c}
$$

$W_{n, \min }$ - required moment of beam strength; $R_{y}$ - calculated strength of the beam material; $\gamma_{c}$ coefficient of working conditions adopted by [15];

To satisfy the requirements of the strength of the overlap, the following conditions must be fulfilled:

$$
M_{1 e x}<M_{1 i n} \text { and } M_{2 e x}<M_{2 i n} \text {. }
$$

In accordance with the norms of [17] the following conditions must be fulfilled:

1. Stiffness ratio

2. Check of stresses in concrete

$$
E_{b} \cdot I_{b} \leq 0.2 \cdot E_{s t} \cdot I_{s t}
$$

$$
\sigma_{b}=M_{2} /\left(\alpha_{b} \cdot W_{b, r e d}\right)-\sigma_{b i}<m_{b} \cdot R_{b}
$$

3. Checking of stresses in the longitudinal reinforcement

$$
\sigma_{s}=M_{2} /\left(\alpha_{b} \cdot W_{b, r e d}\right)+\sigma_{r i}<m_{r} \cdot R_{s c}
$$

4. Checking of stresses in the upper belt of the steel beam

$$
\left(M-z_{b, s t} \cdot N_{b, s}\right) /\left(\mathfrak{x} \cdot W_{f 2, s t}\right)-N_{b, s} / A_{s t}<m_{1} \cdot m_{\mathrm{c}} \cdot R_{y}
$$

5. Checking of stresses on the belt of steel beams

$$
\left(M-z_{b, s t} \cdot N_{b, s}\right) /\left(æ_{3} \cdot W_{f 1, s t}\right)+N_{b, s} / A_{s t}<m \cdot R_{y}
$$

The notation in formulas (7-11) was adopted according to SP 35.13330.2011 "Bridges and pipes" [17]. 
In accordance with the norms [18] the following conditions must be fulfilled:

1. Stiffness ratio

2. Check of stresses in concrete

$$
E_{b} \cdot I_{b} \leq 0.2 \cdot E_{s t} \cdot I_{s t}
$$

$$
\sigma_{b}=M_{2} /\left(\alpha_{b} \cdot W_{b, r e d}\right)-\sigma_{b i}<\gamma_{b i} \cdot R_{b}
$$

3. Checking of stresses in the longitudinal reinforcement

$$
\sigma_{s}=M_{2} /\left(\alpha_{b} \cdot W_{b, r e d}\right)+\sigma_{r i}<\gamma_{s i} \cdot R_{s}
$$

4. Checking of stresses in the upper belt of the steel beam

$$
\left(M-z_{b, s t} \cdot N_{b, s}\right) / W_{f 2, s t}-N_{b, s} / A_{s t}<\gamma_{1} \cdot \gamma_{c} \cdot R_{y}
$$

5. Checking of stresses on the belt of steel beams

$$
\left(M-z_{b, s t} \cdot N_{b, s}\right) / W_{f 1, s t}+N_{b, s} / A_{s t}<\gamma_{c} \cdot R_{y}
$$

The designations in formulas (12-16) are adopted according to SP 266.1325800.2016 "Steel reinforced concrete structures. Design rules" [18].

\section{Results and discussion}

In accordance with the above normative documents, calculations of the strength of combined beams of complex monolithic overclad were performed and the coefficients of the use of materials for different load ranges and different beam sections were found (Figures 2-4 and Table 1).

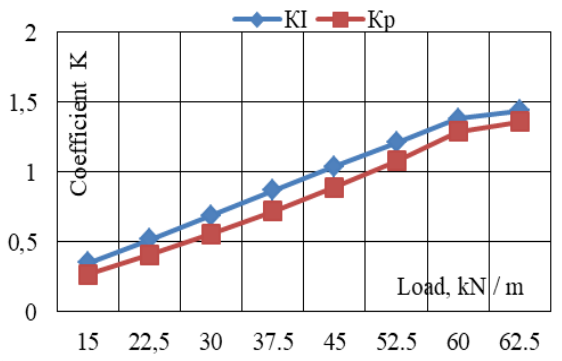

Fig. 2. Coefficients of use $K$ obtained in accordance with [15].

It can be seen from figure 2 that with increasing load, the utilization factors the materials of the beam $K_{\mathrm{I}}$ and the plate $K_{p}$ increase in proportion to the applied load, and the utilization factor of the beam $K_{\text {I }}$ grows slower than the coefficient $K_{p}(30-6 \%)$. At loads above $50 \mathrm{kN} / \mathrm{m}$, the strength of the beam is fully used, and in the slab there is still a reserve of about $10 \%$.
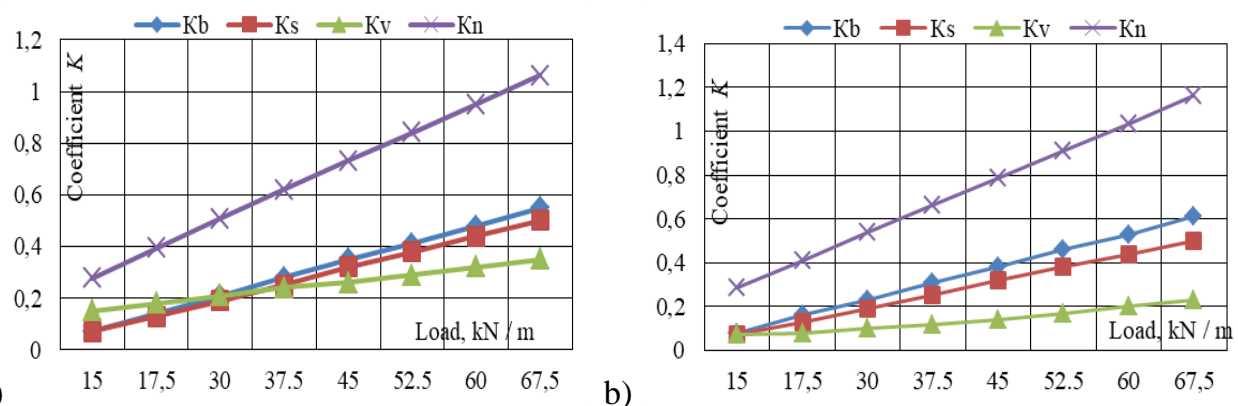

Fig. 3. Coefficients of use $K$. a) - prepared according to [17], b) - prepared according to [18].

It can be seen from figure $3 \mathrm{a}$ that the utilization factor of the material in the lower belt of the beam $K_{n}$ increases from 0.277 to 1.061 and exceeds the remaining strength coefficients of concrete $K_{b}$, the longitudinal reinforcement $K_{s}$, of the material in the upper 
belt of the steel beam $K_{v}$ by 2-3 times, lower beam girdle for simultaneous achievement of utilization factors in all elements of overlap.

It can be seen from figure $3 b$ that the coefficient of utilization of the material in the lower belt of the beam $K_{n}$ increases from 0.288 to 1.16 and exceeds the rest factors of the strengths of concrete $K_{b}$, the longitudinal reinforcement $K_{s}$, of the material in the upper belt of the beam $K_{v}$ by a factor of 2-5, lower beam girdle for simultaneous achievement of utilization factors in all elements of overlap.

Table 1. Coefficient of use of strength of combined beams at different loads

\begin{tabular}{|c|c|c|c|c|c|c|c|c|c|}
\hline \multirow{2}{*}{$\begin{array}{l}\text { Normative } \\
\text { document }\end{array}$} & \multirow{2}{*}{$\begin{array}{c}\text { Coefficient } \\
\text { of use }\end{array}$} & \multicolumn{8}{|c|}{ Load, kN/m } \\
\hline & & 15 & 22.5 & 30 & 37.5 & 45 & 52.5 & 60 & 62.5 \\
\hline \multirow{2}{*}{ [15] } & $K_{I}$ & 0.35 & 0.52 & 0.69 & 0.87 & 1.04 & 1.21 & 1.38 & 1,44 \\
\hline & $K_{p}$ & 0.27 & 0.41 & 0.56 & 0.72 & 0.89 & 1.08 & 1.29 & 1.36 \\
\hline \multirow{4}{*}{ [17] } & $K_{b}$ & 0.07 & 0.14 & 0.21 & 0.28 & 0.35 & 0.41 & 0.48 & 0.55 \\
\hline & $K_{s}$ & 0.07 & 0.13 & 0.19 & 0.25 & 0.32 & 0.38 & 0.44 & 0.5 \\
\hline & $K_{v}$ & 0.15 & 0.18 & 0.21 & 0.24 & 0.26 & 0.29 & 0.32 & 0.35 \\
\hline & $K_{n}$ & 0.277 & 0.394 & 0.508 & 0.62 & 0.73 & 0.84 & 0.95 & 1.06 \\
\hline \multirow{4}{*}{ [18] } & $K_{b}$ & 0.08 & 0.16 & 0.23 & 0.31 & 0.38 & 0.46 & 0.53 & 0.61 \\
\hline & $K_{s}$ & 0.07 & 0.13 & 0.19 & 0.25 & 0.32 & 0.38 & 0.44 & 0.5 \\
\hline & $K_{v}$ & 0.07 & 0.08 & 0.1 & 0.12 & 0.14 & 0.17 & 0.2 & 0.23 \\
\hline & $K_{n}$ & 0.288 & 0.412 & 0.537 & 0.66 & 0.785 & 0.91 & 1.034 & 1.16 \\
\hline
\end{tabular}

Figure 4 shows a comparison of the strength coefficients of the section of the I-beam 35B1, obtained by different methods.

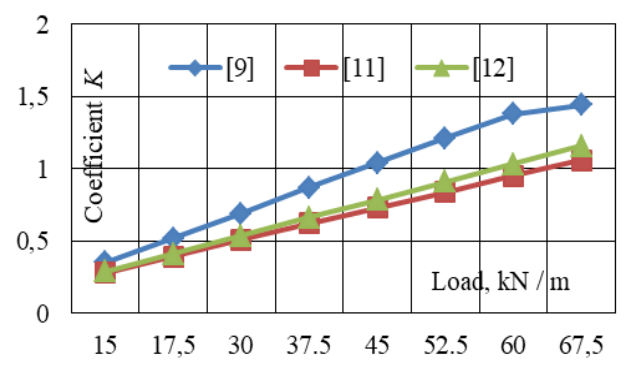

Fig. 4. Coefficients of use of strength of beams.

It can be seen from figure 4 that the coefficient of use of the material of the beam $\mathrm{K}$, calculated in accordance with [15], exceeds the analogous coefficients found by [17] and [18] by 1.2-1.4 times, with the greatest discrepancy at higher loads . The coefficients of the use of the material of the beam K, found from [18], are insignificant (by 4-9\%) higher than the analogous coefficients calculated by [17].

\section{Conclusions}

1. The performed work shows that it is possible to use all the considered methods to calculate the strength of complex overlaps.

2. The largest reserves of strength of materials and overlapping in general give results obtained in accordance with [15].

3. Calculations performed in accordance with recommendations [17] and [18] give close results and can be used to calculate similar structures.

4. The limits of the applicability of calculating the strength of complex overlaps are in accordance with [15] in the range of loads $15 \sim 45 \mathrm{kN} / \mathrm{m}$, and for calculation of strength in accordance with [17] and [18] - $15 \sim 60 \mathrm{kN} / \mathrm{m}$. 
5. Traditional calculation of the strength of a complex overlap, based on the distribution of forces in proportion to the rigidity, can be used for preliminary evaluation calculations of the strength of combined beams, in view of its simplicity and accessibility.

6. The results of this study extend to other types of complex floors, including a reinforced concrete slab, profiled flooring and steel beams.

\section{References}

1. V.S. Babalich, E.N. Androsov Steel-reinforced concrete structures and the prospect of their application in the construction practice of Russia. The successes of modern science. 4, 205-208 (2017)

2. P.I. Egorov, S.A. Korolev Steel reinforced concrete floors Far East: the problems of the development of the architectural and construction complex. 1, 310-313 (2015)

3. A.G. Tamrazyan, S.N. Arutyunyan To the assessment of the reliability of steel slabs of slabs with profiled floorings Herald of Civil Engineers. 6, 52-57 (2015)

4. N.G, Gonshakov, A.G. Gonshakov, M.S. Sergeyev, M.O. Lisyatnikova Determination of capacity of the plate of monolithic reinforced concrete with steel profiled floor, working in two directions Bulletin of construction equipment 12 (1000), 48-49 (2017)

5. G.M. Bazhin Analysis of the tensive status, when the beam covering is included including the joint work of the profiled floor International scientific journal. 6, 61-65 (2017)

6. V.S. Kuznetsov, Yu.A. Shaposhnikova, K.A. Budoshkina, Yu. A. Murlisheva, A.S. Ulyamaev Strengthening of reinforeced concrete floors with pre-stressed rebars Engineering Journal of Don. 2 (2018)

7. V. Cherednikov, O. Voskobiinyk, O. Cherednikova Evaluation of the warping model for analysis of polystyrene concrete slabs with profiled steel sheeting Periodica polytechnica: civil engineering. 61, 3, 483-490 (2017)

8. I. A. Rumyantseva Steel profiled in steel line concrete reinsures Transport construction. 4, 28 (2009)

9. V.S. Kuznetsov, Yu.A. Shaposhnikova, K.A. Budoshkina, Yu. A. Murlisheva, A.S. Ulyamaev Analysis of the operation of combined beams in a wide range of loads Engineering Journal of Don. 2 (2018)

10. E.L. Ayrumyan, N.I. Kamenshchikov, I.A. Rumyantseva Features of the calculation of monolithic slabs of composite slabs on profiled steel flooring Industrial and civil engineering. 9, 21-26 (2015)

11. S.O. Postanen, A.Yu. Berezkina, V.V. Komissarov, M.O. Postanen Steel reinforced concrete floors on profiled steel flooring Young Scientist. 26, 74-76 (2016)

12. A.G. Tamrazyan, S.N. Arutyunyan To the account of profiled flooring as working reinforcement in the calculation of monolithic reinforced concrete slabs for overcoating Industrial and civil engineering. 7, 64-68 (2016)

13. F.S. Zamaliev To the calculation of steel slabs with steel profiled flooring News of Kazan State Architectural and Construction University. 3, 129-134 (2016)

14. A.M. Zulpuev., K. Baktygulov Two-dimensional model of calculation of reinforcedconcrete composite beams by the method of concentrated deformations ARPN Journal of engineering and applied sciences. 4, 1030-1037 (2017)

15. A.A. Umansky Directory of the designer of industrial, residential and public buildings and structures. Calculated-theoretical M., State publishing house of literature on construction, architecture and building materials. (1960)

16. SNiP 35.13330.2011 Bridges and pipes (1984)

17. SNiP 35.13330.2011 Bridges and pipes (2011)

18. SP 266.1325800.2016 Structures of steel reinforced concrete. Design rules (2016) 